\title{
Book Review: Velichenko V.V. HIV \& AIDS - RED BOOKS of HUMANITY? Public warning
}

\author{
Velichenko VV* \\ Moscow Institute of Physics and Technology, Russia
}

*Corresponding author: Velichenko Vladislav Viktorovich, Moscow Institute of Physics and Technology, Russia, Email: vlad.velichenko@mail.ru
Book Review

Volume 5 Issue 1

Received Date: December 10, 2019

Published Date: January 03, 2020

DOI: $10.23880 / \mathrm{ijbp}-16000172$

\section{B00K I - Treatment of HIV infection}

Book I proposes a method of treating HIV infection by means precision setting of the immune system targeted by iterative calculations. Model analysis indicates the possibility of multiple increase the life expectancy of HIVinfected patients by cybernetic methods.

\section{B00K II - War the AIDS epidemic}

Book II examines scenarios for the development of the AIDS epidemic, the prediction of its disastrous consequences. Built the theory of the epidemic, and suggests practical measures for the relief and elimination of the epidemic.

Messages to American colleagues, UN, and Nobel Committee

Keywords: HIV, AIDS, drugs, infection, epidemic, population, death, mathematics, cybernetics, life.

This Russian scientific Monograph continues basic research by Russian researchers [1] and American scientists [2,3], and contains an overview of the content in English.

Monograph confirms the negative forecast for the treatment of HIV by means of medicine and biology. The catastrophic development of the AIDS epidemic is predicted, aggravated by the development of the epidemic of drug addiction.
Monograph presents a new biological method of treatment, unknown to medical practice and biological theories, independently found by the artificial intelligence of our computer as a result of experiments with the American mathematical model of HIV. Experiments on the American mathematical model have shown that this discovery can significantly extend the life of HIV patients.

Monograph can serve as a textbook of cybernetics and a guide to the use of mathematics in medical and biological research for students of all specialties [4-8].

\section{References}

1. Marchuk GI, Romanyukha AA, Bocharov GA (1989) Mathematical modeling of antiviral immune response in viral hepatitis B. Mathematical questions of cybernetics 2: 5-71.

2. Webb GF, Kirschner DE (1996) Using mathematics to understand HIV immune dynamics. Notices Amer Math Soc 43(2): 191-202.

3. Webb GF, Kirschner DE (1997) Resistance, remission, and qualitative differences in HIV chemotherapy. Emerging Inf Dis 3(3): 273-283.

4. Velichenko VV, Pritykin DA (2009) Using of artificial intelligence and computer technologies for developing treatment programs for complex immune diseases-I. Fundamental Applied Math 15: 21-42.

5. Velichenko VV, Pritykin DA (2011) Using artificial intelligence and computer technologies for 


\section{International Journal of Biochemistry \& Physiology}

developing treatment programs for complex immune diseases-II. J Math Sci 172(5): 635-649.

6. Velichenko VV (2017) HIV and AIDS - Red Books of Humanity? Public Warning.

7. Velichenko VV (2018) Cybernetic HIV Treatment. A Review. Biochemistry \& Molecular Biology Journal 4(3): 20 .
8. Velichenko VV (2019) HIV mysteries decrypted by computer artificial intelligence - the american journal of interdisciplinary innovations and research. 1(4): 123-143.

Monograph [6] in Russian with additions in English is available on the Internet in the publishing house "Labirint" / labirint.ru / in Russia, Moscow. 